\title{
Metacognition and Lifelong E-learning: a contextual and cyclical process
}

\author{
LISA WORRALL \& FRANCES BELL \\ University of Salford, United Kingdom
}

\begin{abstract}
Metacognition is arguably an important conceptualisation within the area of lifelong elearning, with many theorists and practitioners claiming that it enhances the learning process. However, the lifelong, cyclical and flexible aspects of 'before', 'during' and 'after' metacognitions within lifelong e-learning (inclusive of whether an 'input' necessarily leads to a completed 'output') seem marginal within current areas of practical and theoretical debate. This article analyses Reeves's (1997) model of web-based learning in the context of the ADAPT project; a study of lifelong learners based in small and medium sized enterprises. The article focuses upon an analysis of this model's view of metacognition, and in the light of the project findings and literature review, aims to put forward an extended and expanded version of the model with reference to lifelong e-learning.
\end{abstract}

\section{An Introduction to Reeves' Original Model}

Learning is a complex process and involves many differing factors and variables that interact with one another to affect the degrees of success or failure of any one particular individual and/or group of individuals. Before the introduction of learning technologies, earlier models sought to visualise these physical and conceptual face-to-face and group-based processes that occurred within traditional institutions of learning, such as schools. Carroll's model of School Based Learning (1963) used five classes of process variables to explain variance in achievement (output), and treated aptitude (the input variable) as being the amount of time that a learner needs to master a unit of instruction. Reeves adapted this model to include a series of dimensions that take into account the potential of web-based learning and of the ways to realise that potential. We will firstly discuss Reeves's original works, with the aim of further extending this model to incorporate a conceptual awareness of the role that metacognition plays in the processes of lifelong e-learning.

\section{After Dimensions}

Reeves's (1997) model stated that constructs like schema, propositions, rules and skills can play a part in the 'Knowledge and Skills' that a person can obtain. Individuals can also utilise, adapt and extend 'Robust Mental Models' (or structures) that enable them to understand new concepts and knowledge and to problem solve. 'Higher Order Outcomes' such as creativity, curiosity and problem-solving abilities can also be the result of learning and need to be measured, as they may have an effect upon learner performance.

\section{Before Dimensions}

'Cultural Habits of Mind' relate to cultural influences that affect learning and problem-solving and how the designers of web-based environments need to be aware of these issues. 'Aptitude and Individual Differences', such as intelligence, preferred learning styles, interests and attitudes can also affect learning processes and behaviours. Reeves argues that there is a need to analyse the 
'Origin of Motivation' of each learner. An 'extrinsic' motivation could be due to, for example, a learner obtaining a vocational qualification in order to gain employment. An 'intrinsic' motivation can occur where knowledge and/or skills are gained due to interests in problem-solving and/or carrying out various tasks. He argues that by its very nature, the World Wide Web will promote 'intrinsic' motivation due to its relatively new educational use, multimedia capabilities and ability to offer greater learner control.

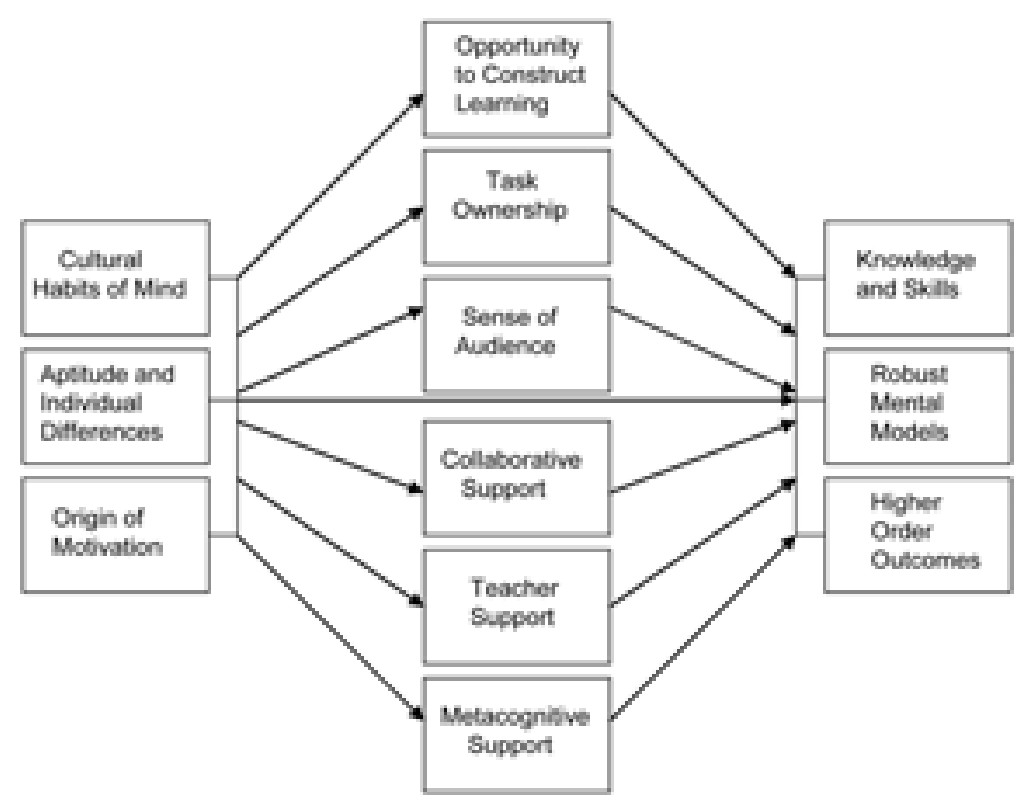

Figure 1. Reeves's (1997) model of World Wide Web based learning.

\section{During Dimensions}

The 'during' dimensions shed light on the processes of learning and link it into the context in which it can be applied. According to Reeves (1997), there is considerable evidence that learning is promoted when learners are given the 'Opportunity to Construct Learning' and with 'Task Ownership' where they are given greater control over what and how they approach and learn content. In the context of learning in formal education, learning tasks can be primarily academic (e.g. essay writing) or authentic (e.g. conducting specific chemical analysis research). Whereas academic tasks may consist to a large degree of memorising data, names, theories, etc., authentic tasks might involve more practical activities that learners feel that they own for themselves to complete. Cognitive learning theory suggests that differences in the way that knowledge is initially gained may affect how it can be used and applied in future differing contexts. Therefore, the potential benefit of web-based learning is that in addition to academic tasks, authentic tasks could also be catered for.

Reeves (1997) argues that each learner's 'Sense of Audience' through the publication of opportunities afforded when learning on the Web will encourage the sharing of knowledge and the enthusiasm to learn. He states that the growth in the number of tools for web-based group work will enable the facilitation of 'Collaborative Support' and also argues for the need to provide 'Teacher Support'. ADAPT project constraints significantly limited the interactivity described in these three dimensions, since the learning opportunities were mainly individuals interacting with computer-based packages, placing a greater emphasis on the last dimension of 'Metacognitive Support', which, as term and concept, will be specifically defined and analysed later in this article. 


\section{What is Lifelong E-learning?}

Reeves's model was designed with regard to e-learning via the World Wide Web. So what is learning and, specifically, what is lifelong e-learning? Schoenfeld (1999, p. 6) defined 'learning' as the process of 'coming to understand things and developing increased capacities to do what one wants or needs to do'. The European Lifelong Learning Initiative defines 'lifelong learning' as:

The development of human potential through a continuously supportive process which stimulates and empowers individuals to acquire all the knowledge, values, skills and understanding they will require throughout their lifetimes. (ELLI, 2001)

According to Luckin et al (2004), the concept of 'e-learning' has been outlined by the UK Department for Education and Skills consultation document, 'Towards a Unified E-learning Strategy', as occurring with the usage of information and communications technologies (ICTs). There are also terms like 'networked learning', which can be defined as the usage of ICTs that promote connections between learners, tutors, communities and their resources (Goodyear, 2001). However, the extent of the 'freedom' of these connections is very much open to debate (Lankshear, 2006). Interactivity can be cyclical and occur with an exchange of concepts and ideas between people, things and technologies (Luckin \& du Boulay, 2002). E-learning can also be 'blended' in terms of its combination of delivery media, instructional, online and face-to-face (F2F) methods Driscoll (2002).

'Open Learning' is a term utilised by the Open University (2001) to refer to learning that occurs without restrictions on age, place or space and where learners can be more self-directed in what, where and how quickly they learn and when they are assessed. 'Distance Learning' involves a specific part of 'Open Learning' that refers to tutors and learners being geographically separated. It can be argued that, taken as a whole, 'lifelong e-learning' presents a 'grand challenge' of the need to incorporate these concepts while also being able to evolve throughout an individual's lifetime (Hall, 2002, p. 1).

We agree with Jones (2004) that the theoretical and disciplinary backgrounds of learning technologies are far too numerous and diverse to comprehensively analyse and discuss. In itself, Reeves's model goes far in attempting to incorporate the concepts of e-learning, but not of 'lifelong e-learning', since the model presents e-learning as a singular 'input/output' process. It is with specific regard to this cyclical and self-directed aspect of its design and usage that we present the model in this article.

\section{Metacognition: what exactly is it?}

Reeves (1997) locates his conception of metacognition as a process that takes place 'during' learning. Metacognition has been defined as:

one's knowledge concerning one's own cognitive processes or anything related to them ... For example, I am engaging in metacognition if I notice that I am having more trouble learning A than B; if it strikes me that I should double check C before accepting it as fact. (Flavell, 1976, p. 232)

Although Flavell is usually credited with coining the term metacognition, the roots of this concept can be traced back as far as Socrates (380 BC). The Socratic Method is a dialogic method of inquiry where a teacher asks students questions that expose errors in order to improve their reasoning processes. Since this dialogue provokes self-reflection by a student, it plays an important role in facilitating metacognition within a group or social setting. Flavell argued that metacognitive processes are affected by person variables (of individual and group knowledge), task variables (of nature and difficulty of learning tasks) and strategy variables (of how to best approach learning tasks) (Flavell, 1979). People are also emotional beings, whose reflections on experiences of enjoyment, confusion, anxiety or frustration when learning can affect their future expectations of success or failure and their decision on whether or how to continue learning (Flavell, 1976; Brown, 1987). People can go beyond their lived experiences by creatively imagining novel situations and activities prior to predicting outcomes that can affect attitudes, behaviours and self-regulations (Cook, 1998). 
Besides being individual, social and emotional beings, humans also develop over time. Hertzog \& Hultsch argue that metacognition operates differently over an individual's lifetime. During youth there is a tendency to over-estimate ability to learn new information. This changes to under-estimation in later life, based on the belief that memory and learning ability automatically decline in old age. Unfortunately, this can become a self-fulfilling prophecy that reduces learning potential. These potentially negative self-beliefs can be removed by providing learners with more positive metacognitive insights into the learning process (Hertzog \& Hultsch, 1992). As people are living longer, lifelong learners represent a growing target group for learning, and for whom metacognition may play an important role in their empowerment. We shall discuss later in this article how Reeves's original model does not include an awareness that metacognition is a lifelong process.

\section{Theory and Methodology}

This article bases its perspective within the realm of social constructivism, a theoretical stance that is encompassed within Reeves's (1997) original model. Knowledge construction is seen as a random variation of existing knowledge, metacognitive processes and the selective retention of new knowledge that assists an individual within their specific environment. Social constructivists do not necessarily deny the existence of objective reality. They do, however, deny the existence of objective knowledge. Knowledge is perceived as being relative and subject to constant change according to differing biological, psychological, social and environmental processes. Epistemologically, social constructivists have no specific viewpoint regarding the existence of entities, but if they do exist, they are seen as having little (or no) effect upon individuals. Ontologically, these entities, if they exist, are perceived as being formed via processes of social interaction.

\section{Selection of SMEs and Learners}

Small and medium sized enterprises (SMEs) and individuals from the North West Region of England were identified from a number of contacts gained through prior research projects. The learner base was mixed (of varying ages, sex, occupation) and the learners were given the opportunity of using both online and CD-ROM-based courseware at home, work or anywhere where they have access to a personal computer (PC). A courseware brochure was created to provide an immediate source of reference when choosing courseware.

The gender distribution consisted of 26 male learners and 14 female learners aged between the ages of 18 and 60. Twenty-one learners left during the implementation of the ADAPT project. The formal number of participants investigated comprised 19 males and 6 females. The degree of computer literacy ranged from those who had practically no knowledge of computers and the Internet, to those who were quite proficient.

\section{Apparatus}

Online learning objectives and learning journal facilities were produced to enable learners to write down their original learning objectives and motivations for learning (in line with the 'Origin of Motivation' dimension). Due to project constraints, the ADAPT project was unable to provide specific 'Metacognitive Support' (e.g. with a mentor or tutor). However, the learner journals were designed as 'self-help' tools that enabled learners to self-reflect upon their own learning processes and behaviours. The learners were also given an online post-course questionnaire that was used to gain quantitative and qualitative data on the usability aspects of the courseware in line with general SME e-learning project research targets and objectives.

The results generated by the post-course questionnaire for each training module were analysed after being filtered through a series of excel spreadsheet templates that analysed the positive and negative Likert ratings of learners on the usability aspects of the user interface, time length and applicability, package support, assessment and data feedback, package multimedia and general overview of each courseware package. These questions also included open-ended sections 
where each learner was given the opportunity to elaborate on the reasons for their answer. A generic qualitative and quantitative exit questionnaire was also used to assess their views, opinions and experiences of the project-based learning process as a whole.

\section{Procedure}

At the beginning of each course, learners submitted learner objectives of what their original aims, objectives and/or motivations for learning actually were. Whilst engaged in learning, they were asked to complete an ongoing reflective learning journal. This journal had a dual role: to encourage metacognition and to provide valuable research data. Learners were asked to outline areas such as learner successes and problems, moments of great advances in understanding, attitudes and feelings, thinking strategies, achievements, how easily the learning process fitted into their current workload, and whether they thought their support needs were met. Learners were also asked to offer their opinions of areas where they thought that improvements were needed.

After completing a course, learners were required to fill in the post-course questionnaire. This questionnaire was designed to provide both quantitative and qualitative data from learners on various usability aspects of the courseware that they had recently used. Learner feedback was then gathered from an exit questionnaire (following completion of the entire learning process) to analyse if there were any alterations in learner responses and feedback over the longer term.

\section{The Case for 'Mixed-Method' Evaluation}

Greene \& Caracelli (1997) refer to the usage of mixed methods and the integration of diverse paradigms when outlining the potential integration and utilisation of differing theoretical perspectives, methodologies and research tools. They state that there are three main perspectives: (1) the 'purist' stance is against combining paradigms, but uses mixed methodologies; (2) the 'pragmatic' stance views paradigms as useful conceptualisations, but due to practical considerations, uses mixed methods within specific contexts, and (3) the 'dialectical' stance. This stance views paradigms as being essential research frameworks that when mixed, can generate positive tensions that provide more insightful avenues of research and deeper levels of evaluative knowledge.

From the standpoint of Greene \& Caracelli's (1997) categorisations, we employed a 'pragmatic' mixed-method approach, since the research incorporated a contextually based social constructivist perspective. However, the ADAPT ICT research strand (undertaken by the present authors) was based within a larger ADAPT project that utilised differing researcher strand paradigms and methodologies.

This article does not attempt to generalise the research results beyond the specific contextual research base onto a wider societal scale, which Greene \& Caracelli (1997) identify as conceptually possible within a more 'dialectical' stance. In order to achieve this, a longitudinal study would be required, based upon a much greater number of learners, and based within a greater range of learning and training environments, backgrounds, ages, cultures, ethnic and social groupings and so on, in order to potentially provide wider societal inferences and/or conclusions. The data gathered is limited and largely descriptive in nature, based within specific time, space and person groupings that have been analysed, and the research data is viewed and analysed within a social constructivist perspective.

\section{Cyclical Flow Model or Continuum}

The work on Reeves's dimensions has been developed by Reeves and other authors by treating each dimension within a singular continuum (Reeves \& Reeves, 1997). Kanuka \& Anderson discuss the constructivist/instructivist debate and argue for the need for a constructivist approach that facilitates contextually rich, meaningful and authentic learning that in turn encourages selfreflection (Kanuka \& Anderson, 1999). The World Wide Web can facilitate self-reflection by providing opportunities for people to re-examine content and concepts, and to assess how each learning process was constructed (Hazzan, 2004). Koper \& Tattersall (2004) argue that there is a 
need to establish a Learning Network (LN) architecture of technologies that more accurately and flexibly meets and records individual lifelong learning needs and requirements. This can be conceptualised by extending the input-process-output shown in Figure 1 into a cyclical flow model that can capture the complex processes and interactions occurring between and within dimensions and learning activities over an individual's lifetime.

\section{An Extension and Adaptation of Reeves's Model}

Metacognition: a 'before' expansion

An important question arises: To what extent does prior knowledge of metacognitive processes (and an individual's level of awareness, monitoring and/or regulative abilities of them) affect the effective utilisation of e-learning technologies, learner processes and behaviours? With reference to this specific and centrally important question, we would like to put forward the new 'Metacognitive Processes' dimension. It should first be stated that there is no empirical data reported in this article to support this dimension. This is potentially a very large and specialist area of research which was not covered within the constrained parameters of the ADAPT project. However, the literature review highlighted that learner prior metacognitive processes can be analysed and assessed by the usage of metacognitive assessment inventories, tools and methods that can affect the design and delivery of effective e-learning tools, technologies and services.

Supporting literature for this dimension includes the works of Flavell (1976), who states that metacognition consists of an awareness of an individual's own processes and that these processes consist of both metacognitive knowledge, experience and/or regulation. Brown (1987) states that metacognition consists of knowledge and regulation of cognition. Cook (1998) states that in addition to Brown's (1987) categorisations, individuals can utilise a sub-process of 'going beyond' (at a meta-level) to within, for example, musical composition environments, by creatively imagining novel situations and activities prior to learning outcomes. This dimension stipulates that there is a conceptual need to view knowledge of metacognition as separate to knowledge of content. An assessment of an individual's awareness of level and type of metacognitive abilities can facilitate (1) content learning and/or (2) metacognitive training by providing targeted insights into learner prior abilities and areas of weakness or strength. An interesting question arises as to the ideal balance of training in metacognition and/or content, and further work is required to ascertain this. It could be argued that there is a great degree of cross-fertilisation between the 'Aptitude and Individual Differences', 'Origin of Motivation' and 'Opportunity to Construct Learning' dimensions, as they outline the potential influence of individual characteristics regarding (inclusive of potential 'digital divides') upon learning processes and behaviours. A clearer picture of learner self-perceptions, skills and abilities can assist both learners and practitioners in guiding the prior targeted provision of learning content, technologies and metacognitive support tools.

\section{Metacognition: a 'during' expansion}

Within the original model, Reeves (1997) outlines an awareness of the need to provide 'Metacognitive Support' and of Flavell's (1979) arguments that metacognitive support strategies can facilitate learners in the evaluation and progression of their learning strategies and behaviours. Reeves (1997), however, did not centrally outline variations of 'Self-Direction' and for this reason we wish to include this extended conceptualisation. Learners may (and were shown to have done so in the ADAPT project) reject the offer of support altogether. Of the 25 learners (out of an original starting number of 40) that completed their training, only $16(64 \%)$ utilised any part of the online metacognitive tools on offer. This leaves a large percentage $(44 \%)$ that chose not to use the metacognitive support tools at all. Reasons given ranged from not perceiving the benefit of using them, to those that felt technically or metacognitively unable to use them. Of those who used them, views ranged from, for example, learner 5006, who stated that 'basically I find it essential to take notes', to learner 1005, who stated, 'boredom ... other priorities' and learner 1014, who stated that they were unable and unwilling 'to find the time'.

Flavell (1976) argues that learners continuously reflect upon their levels of ability, the nature of the task and individual learning experiences, to assess whether there is a need to regulate/alter 
their current learning strategy and behaviours. McKoon \& Ratcliff (1992) argue that some learners may also be unable to verbalise their metacognitive acts because some of them may have become internalised (i.e. internally automated). Tobias \& Everson (2000) argue that some learners may over- or under-estimate their levels of understanding. Variations can also occur in technological abilities, which result in 'digital divides' (in terms of how 'usable' technologies are to certain people with varying levels of knowledge and skills (Davis, 1989). This dimension possesses a degree of cross-fertilisation with the 'Aptitude and Individual Differences' and 'Opportunity to Construct Learning' dimensions, as the level of complexity (and interest) in using various learning technologies and support tools will affect aspects of their uptake and utilisation.

\section{Metacognition: an 'after' expansion}

Reeves (1997) did not demonstrate awareness that learning and knowledge construction is not a singular journey. Knowledge construction is strengthened through its re-application, reflection and utilisation. For this reason, we would like to add a 'Metacognitive Analyses' dimension. This dimension brings forward the affective, cyclical and adaptive conceptualisation of learning (inclusive of whether or not an 'input' necessarily leads to a completed 'output').

Self-reflections are not just based upon a learner's increased awareness of strategies and processes of learning, but also upon whether they consider their learning to be targeted, relevant and interesting. For example, learner 2003 viewed their training to be irrelevant to their needs and so abandoned their course and stated 'I realised this was the wrong thing to do, so have called it a day'. Learners can also affectively self-reflect upon their prior experiences and this will invariably impact upon present and future expectations of success or failure and learner processes and behaviours (Flavell, 1979). An example of this can be found from learner 5003, who stated that their 'experience gained' from a prior training package directly affected their decision to receive further courseware.

Literature review insights support this viewpoint. Ayer ([1936] 1995) argues that what we refer to here as 'metacognitions' are experiential. Popper ([1972] 1979) argues that knowledge is gained with the modification of prior knowledge and with critical investigation. Wittgenstein (1953) utilises the analogy of learning as that of an individual who criss-crosses a landscape in a journey of critical discovery where they revisit and reflect upon learning content from many differing directions, in order to further their understanding of it. Learner 1003 outlined an example of this process by stating that they learned more deeply when they 'go over' content from many differing perspectives. Learner 2018 stated that they liked the design of the technology that enabled them to 'go back and review the section again to understand the reasoning behind the correct answers'.

Hertzog \& Hultsch (1992) state that metacognitive knowledge and affective expectations continually evolve over an individual's lifespan. According to Pask (1975), an individual's ability to remember and retain knowledge is affected by social and contextual parameters. Similar arguments are also outlined by theorists like Goodyear (2001), Goodyear et al, 2004) and Steeples \& Jones (2002). There was evidence in the journals that learners had reflected upon how they had learned with regard to their individual learning styles (Gardner, 1999). Learner 1003 exemplifed 'Visual spatial' thinking by stating that 'The visual learning for me has been very beneficial, my memory tends to recall pictures and events ... the graphics are easier for me to recall'.

A further question arises: To what extent do learning technologies have an effect upon an individual's metacognitive analyses? Luckin $\&$ du Boulay (2002) argue that interactivity can occur between peers, tutors and interactive and communicative digital systems. Salmon (2002, [2000] 2004) states that the e-moderator can facilitate learner self-reflections within computer-mediated communications (CMC) and Twidale (2000) observes that these interactions can also incorporate physical 'over the shoulder' collaborations with other learners. Jonassen \& Reeves (1996) and Reeves et al (2002) outline the importance of designing authentic and reflexive learning. Chi et al (1989) argue that learners can vary in terms of both their metacognitive processes and their technological abilities. 'Digital divide' issues of knowledge and skills also surround usability aspects of technologies (Davis, 1989). Jonassen et al (1998) state the need to aid the facilitation of metacognition with the design of computer based 'mindtools'. 
The list of theorists and models is by no means exhaustive, but it serves to highlight that there is already a large body of thought that shows an awareness of the concept of incorporating 'Metacognitive Awareness' within current (and future) models of lifelong e-learning. It could also be argued that there is a strong degree of cross-fertilisation with the 'Aptitude and Individual Differences', 'Collaborative Support' and 'Opportunity to Construct Learning' dimensions, as, whether simulated, facilitated or real, learner reflexivity and constructed learning is facilitated through use of a range of differing types of systems. Ascertaining the efficiency and effectiveness of learning with regard to differing individual abilities, mechanisms, metacognitive facilitations and designs and modes of delivery would constitute an interesting area of future research.

Within Figure 2, the unbroken lines represent Reeves's (1997) original dimensions. The short dashed lines represent amended/extended dimensions. The long dashed lined boxes represent new conceptual dimensions. The double-ended arrows connecting the dimensions illustrate a generic awareness of the cross-fertilisations that occur both within and between dimensions (i.e. the conceptualisation of how one dimension may potentially impact upon another).

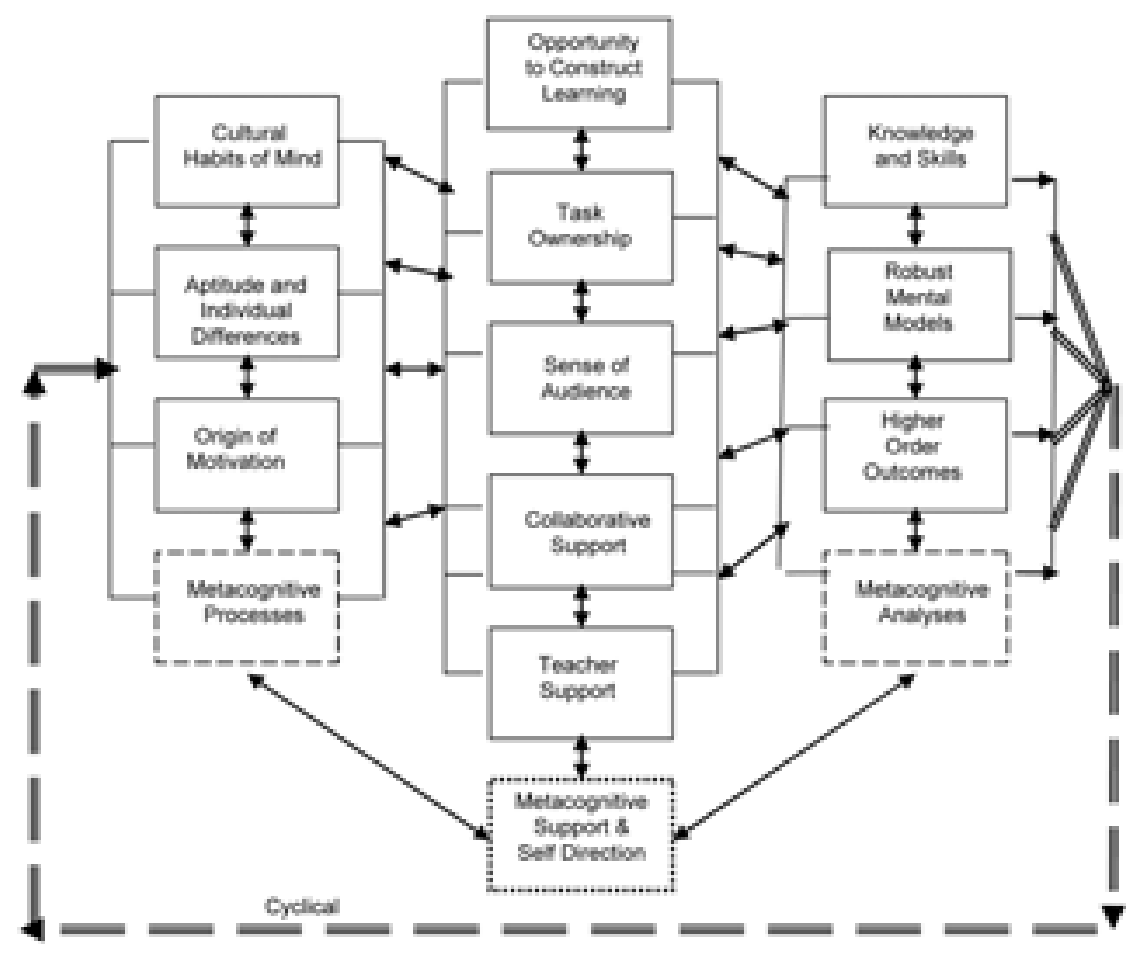

Figure 2. Amended and adapted version of Reeves’s (1997) model.

The dashed double-lined flow arrows (surrounding the right side, lower and left side of the model and travelling in a clockwise direction) represent e-learning as being a lifelong cyclical process, rather than the singular 'input/output' process as conceptualised in Reeves's (1997) original model. Within any singular learning activity, an 'input' does not necessarily lead to a completed 'output'. Individuals are not a tabula rasa (i.e. clean tablet) onto which learning content can be written. This amended and extended model presents e-learning as a lifelong and cyclical process, supported by self-reflection processes before, during and after each learning activity. Learning processes and behaviours can 'succeed' or 'fail' and each subsequent cyclical event can affect an individual's present and future expectations and learning behaviours over the course of their lifetime. 


\section{Conclusion: a model for what and for whom}

In this article we have pursued enhancement of Reeves's model to extend the concept of learner metacognitions, and in subsequent publications we shall introduce additional enhancements to the model. We have argued that learners' experiences can be improved by engaging in metacognitive activities before, during and after each learning activity. Tutors and learning technologists who configure e-learning environments can include relevant metacognitive activities and support resources, bearing in mind learner differences in skills, knowledge, abilities and preferences for metacognition. This is particularly important for individual learners who may engage in solo learning activities without the benefit of social interaction with other learners.

Learners may experience 'leaps' of understanding in their self-awareness of their thinking strategies, and this may be seen as more important than advancements in content knowledge. However, the question arises as to what is the ideal balance between content knowledge and skills acquisition, and the training of effective metacognitive knowledge and skills. The cyclical nature of the model raises questions with each individual's learning experience of: How did this occur? How was it facilitated or hindered? How (if possible) can it be improved? The autonomy of lifelong learners is a key factor. So is awareness of their differing levels of skills, knowledge and abilities in communicating their metacognitive processes and acts, as well as their ability to utilise technological support tools and technologies on offer. Learning activities are unlikely to proceed according to a 'grand plan' owned by an employer or some other agency. Hence, it is essential that learners 'own' this cyclic model of their personal development alongside a 'dialogue' with the learning practitioner within a 'constructivist shift', i.e. towards constructivism that facilitates learner managed and directed, collaborative usage (i.e. dynamic and 'real world' applicable, knowledge based and holistic systemic approaches) (Goodyear, 2001). This targeted and dialogic contextualised design and delivery approach holds great relevance when considering the time and resource-based constraints within SMEs.

The literature review and limited empirical analysis of Reeves's (1997) original model have indicated that the lifelong, cyclical and flexible aspects of metacognitive processes within e-learning are largely absent within current areas of practical and theoretical debate. The concept that an 'input' does not necessarily lead to a completed 'output', as varying factors and dimensions may help or hinder the learning process, is also largely absent. In response, the contribution of this article puts forward a flexible, adapted and extended version of Reeves's (1997) model. Our research has provided a partial testing of the adapted and extended model within an extended literature review and we encourage practitioners to apply the model to their own practice in the light of the discussion above.

\section{References}

Ayer, A.J. ([1936] 1995) Language, Truth and Logic, 2nd edn. Oxford: Oxford University Press.

Brown, A.L. (1987) Metacognition, Executive Control, Self-Regulation and Other More Mysterious Mechanisms, in F.E. Weinert \& R.H. Kluwe (Eds) Metacognition, Motivation and Understanding. Mahwah: Erlbaum

Carroll, J.B. (1963) A Model of School Learning, Teachers College Record, 64, 723-733.

Chi, M.T.H., Bassok, M., Lewis, M., Reimann, P. \& Glaser, R. (1989) Self-explanations: how students study and use examples in learning to solve problems, Cognitive Science, 13, 145-182.

Cook, J. (1998) Mentoring, Metacognition and Music: interaction analyses and implications for intelligent learning environments, International Journal of Artificial Intelligence in Education, 9, 45-87.

Davis, F.D. (1989) Perceived Usefulness, Perceived Ease of Use, and User Acceptance of Information Technology, MIS Quarterly, 13(3), 319-340. http:/ / dx.doi.org/10.2307/249008 (accessed 30 June 2007).

Driscoll, M. (2002) Blended Learning: let's get beyond the hype. http:/ / elearningmag.com/ltimagazine/article/articleDetail.jsp?id=11755 (accessed 2 May 2006).

ELLI (2001) European Lifelong Learning Initiative. http:/ / www.noesis.se/ (accessed 15 March 2006).

Flavell, J.H. (1976) Metacognitive Aspects of Problem Solving, in L.B. Rensick (Ed.) The Nature of Intelligence. Mahwah: Erlbaum. 
Flavell, J.H. (1979) Metacognition and Cognition Monitoring: a new area of psychological inquiry, American Psychologist, 34, 906-911. http:/ / dx.doi.org/10.1037/ 0003-066X.34.10.906 (accessed 30 June 2007).

Gardner, H. (1999) Intelligence Reframed: multiple intelligences for the 21st century. New York: Basic Books.

Goodyear, P. (2001) Effective Networked Learning in Higher Education. Notes and Guidelines. Centre for Studies in Advanced Learning Technology, Lancaster University. http:/ / csalt.lancs.ac.uk/jisc/ (accessed 15 April 2007).

Goodyear, P., Avgeriou, P., Baggetun, R., Bartoluzzi, S., Retalis, S., Ronteltap, F. \& Rusman, E. (2004) Towards a Pattern Language for Networked Learning. Paper presented at Networked Learning Conference 2004.

http:/ / www.networkedlearningconference.org.uk/past/nlc2004/proceedings/individual_papers/good year_et_al.htm (accessed 30 June 2007).

Greene, J.C. \& Caracelli, V.J. (1997) Advances in Mixed-Method Evaluation: the challenges and benefits of integrating diverse paradigms, San Francisco: Jossey-Bass.

Hall, W. (2002) Grand Challenge: lifelong e-learning. http:/ / www.nesc.ac.uk/esi/events/Grand_Challenges/panelc/c15.pdf (accessed 5 September 2006).

Hazzan, O. (2004) Mental Constructions of Web Site: learner and teacher points of view, British Journal of Educational Technology, 35(3), 323-344. http:// dx.doi.org/10.1111/j.0007-1013.2004.00392.x (accessed 30 June 2007).

Hertzog, C. \& Hultsch, D.F. (1992) Metacognition in Adulthood and Old Age, in F.I.M. Craik \& T.A. Salthouse (Eds) Handbook of Cognitive Aging, 417-466. Mahwah: Erlbaum.

Jonassen, D.H. \& Reeves, T.C. (1996) Learning with Technology: using computers as cognitive tools, in D. Jonassen (Ed.) Handbook of Research for Educational Communications and Technology. New York: Simon Schuster Macmillan.

Jonassen, D.H., Carr, C. \& Yueh, H.P. (1998) Computers as Mindtools for Engaging Learners in Critical Thinking, TechTrends, 43(2), 24-32.

Jones, C. (2004) Theory and Practices of Learning Technology. Paper presented at Networked Learning Conference 200.

http:/ / www.networkedlearningconference.org.uk/past/nlc2004/proceedings/symposia/symposium1 / jones.htm (accessed 12 October 2006).

Kanuka, H. \& Anderson, T. (1999) Using Constructivism in Technology-Mediated Learning: constructing order out of the chaos in the literature, The International Consortium for the Advancement of Academic Publication (ICAAP). http://radicalpedagogy.icaap.org/content/issue1_2/02kanuka1_2.html (2 December 2006).

Koper, R. \& Tattersall, C. (2004) New Directions for Lifelong Learning Using Network Technologies, British Journal of Educational Technology, 35(6), 689-700. http:/ / dx.doi.org/10.1111/j.1467-8535.2004.00427.x (accessed 30 June 2007).

Lankshear, C. (2006) Freedom and Sharing in the Global Network Society, E-Learning, 3(3), 396-410. http: / / dx.doi.org/ 10.2304/ elea.2006.3.3.396 (accessed 30 June 2007).

Luckin, R. \& du Boulay, B. (2002) Construction and Abstraction: contrasting methods of supporting model building, in P. Brna, M. Baker, K. Stenning \& A. Tiberghien (Eds) The Role of Communication in Learning to Model. Mahwah: Erlbaum.

Luckin, R., Coultas, J. \& Boulay, B.(2004) Learning with E's: putting technology in its place, in P. Isaias, P. Kommers \& M. McPherson (Eds) Proceedings of the IADIS International Conference, 903-906. http: / / www.cogs.susx.ac.uk/users/bend/papers/ esociety2004.pdf (accessed 10 April 2007).

McKoon, G. \& Ratcliff, R. (1992) Inference during Reading, Psychological Review, 99, 440-466. http: / / dx.doi.org/ 10.1037/ 0033-295X.99.3.440 (accessed 30 June 2007).

Open University (2001) Open Learning. http:/ / www.open.ac.uk/text-only/spotlight.html (accessed17 March 2006).

Pask, G. (1975) Conversation, Cognition, and Learning. New York: Elsevier.

Popper, K.R. ([1972] 1979) Objective Knowledge, revised edn. Oxford: Oxford University Press.

Reeves, T.C. (1997) A Model of the Effective Dimensions of Interactive Learning on the World Wide Web, Proceedings of Interakiivinen Koulutuksessa (ITK). Hameenlinna: Finland.

http: / /it.coe.uga.edu/ treeves/WebPaper.pdf 23-31 (accessed 5 August 2006).

Reeves, T.C. \& Reeves, P.M. (1997) Effective Dimensions of Interactive Learning on the World Wide Web, in B.H. Khan (Ed.) Web-Based Instruction, 59-66. Englewood Cliffs: Educational Technology Publications. 
Reeves, T.C., Herrington, J. \& Oliver, R. (2002) Authentic Activities and Online Learning, in A.J. Goody, J. Herrington \& M. Northcote (Eds) Quality Conversations. Research and Development in Higher Education, 25, 562-567. Perth: HERDSA.

Salmon, G. ([2000] 2004) E-Moderating: the key to teaching and learning online, 2nd edn. London: Taylor \& Francis.

Salmon, G. (2002) Mirror Mirror On My Screen - exploring online reflections, British Journal of Educational Technology, 33(4), 379-391. http: / / dx.doi.org/10.1111/1467-8535.00275 (accessed 30 June 2007).

Schoenfeld, A. (1999) Looking toward the 21st Century: challenges of educational theory and practice, Educational Researcher, 28(7), 4-14. http:/ / dx.doi.org/10.2307/ 1176136 (accessed 30 June 2007).

Socrates (380 BC) Meno: by Plato, trans. B. Jowett, 1871. http:/ / classics.mit.edu/Plato/meno.html (accessed 2 August 2006).

Steeples, C. \& Jones, J. (2002) Networked Learning: perspectives and issues. London: Springer-Verlag.

Tobias, S. \& Everson, H. (2000) Assessing Metacognitive Knowledge Monitoring, in G. Schraw \& J. Impara (Eds) Issues in Measurement of Metacognition, 147-222. Lincoln: Buros Institute of Mental Measurement.

Twidale, M.B. (2000) Interfaces for Supporting Over-the-Shoulder Learning, in M. Benedict (Ed.) Proceedings on Human Interaction with Complex Systems, 33-37. Chicago: University of Illinois.

Wittgenstein, L. (1953) Philosophical Investigations. New York: Macmillan.

LISA WORRALL is a Research Fellow at the University of Salford, United Kingdom. Her research interests include metacognition and lifelong e-learning and she has recently gained a $\mathrm{PhD}$ within this area involving the development of cyclical model concepts. She is currently involved in a number of research projects that facilitate the encouragement of organisational diversity. Correspondence: Lisa Worrall, School of the Built Environment, University of Salford, Maxwell Building, The Crescent, Salford M5 4WT, United Kingdom (1.j.worrall@salford.ac.uk).

FRANCES BELL is Senior Lecturer in Information Systems at the University of Salford, United Kingdom. Her research interests include staff and student international online collaboration (see http: / / www.cabweb.net) and the application of information system theories to online learning and education, both formal and informal. She is currently involved with two projects, one where older people use the Internet to learn more about living with coronary heart disease; and another 'Know and Network' project that researches the diversity of the information needs of women. 